\title{
Translation of Constant Rheme Progression in Mencius
}

\author{
Yuan Tao \\ School of Foreign Languages, Dalian University of Technology, China \\ Email: taoyvan@gmail.com
}

\begin{abstract}
As a key theory of functionalism, thematic progression lays stress on the sequence of sentences for the construction of a coherent discourse. Mencius, the gem of Confucianism, impresses the readers with its profound philosophy and the meticulous logic. A striking feature in the text is the application of many constant rheme progressions which reinforce the information unit in the rheme and enhance the meaning potential in the text. On the basis of the comparison and descriptive study of three authoritative English versions of Mencius, this thesis attempts to suggest the translation strategies of constant rheme progression in the Chinese canon.
\end{abstract}

Index Terms - constant rheme progression, reproduction of structure, substitution and ellipsis, focus permutation

\section{INTRODUCTION}

As a way to fulfill the metafunctions of language, thematic progression focuses on the language system and the interconnection among its subsystems. Mencius, a canon of Chinese classics strikes the readers not only with the eloquent argumentation but also the various sentence structures which cover almost all the thematic progressions. The constant rheme progressions applied in the book have evolved into many popular idioms and proverbs in Chinese. Therefore it is of great value to probe the translation strategies of the special sentence structure.

\section{CONSTANT Rheme Progression}

The concept of theme and rheme goes back to Vilem Mathesius(1939) of Prague School in his work Functional Sentence Perspective. Theme serves as "the point of departure of the message (Halliday and Matthiessen, 2008, p.64)" and rheme the rest of the clause as an elaboration of the theme. In his On Linguistic Analysis of Text Structure, Frantisek Danes $(1974,1989)$ postulates three main types of thematic progression as simple linear progression, TP with a constant (continuous) theme and TP with derived theme. M.A.K. Halliday (1994) analyzes a full investigation on thematic structure from the perspective of functional grammar. Xu Shengheng (1982) proposed focused TP and crossing TP. Downing (2001) applies thematic progression into text analysis. Thomas Bloors(2001) proposes the new TP of split rheme. Geoff Thompson (2008) further develops Danes' Thematic progressions with several special thematic structures. Although definite thematic progressions are still controversial in the field, they are generally classified into five basic types of constant theme, constant rheme, linear progression, derived theme and split rheme.

Constant rheme progression is also known as focused rheme progression in which the rheme is shared by various themes. Diagrammatically, the pattern can be represented in Figure 1 below:

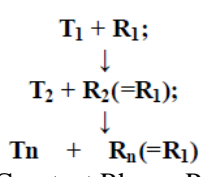

Figure 1. Constant Rheme Progression

Take Nelson Mandela's inaugural address as an example: "The time for the healing of the wounds has come. The moment to bridge the chasms that divide us has come." is a typical illustration of constant rheme progression, in which different themes are arranged according to the priority of time, space, and meanings etc. The information unit is a structure composed of two parts: the Given and the New. In most cases, the theme is the Given and rheme the New. While in constant rheme progression the theme is loaded with something unknown and the rheme is the Given which is repeated for the purpose of emphasis. The clauses are organized with similar sentence structures to elaborate the same feature of different themes. The information unit is reinterated by the tide-like clauses with parallel, rising or falling themes dependent on each other. As a result, the constant rheme progressions form an impressive and cohesive chain.

Systemic Functional (SF) theory views language as a system network or meaning potential to analyze how people express meanings in context. The application of SF theory in the translation of Chinese canon can help the translator better understand the cohesion and textural organization both in the SL and TL. 


\section{TRANSLATION OF MENCIUS IN WESTERN WORLD}

Known as "the second sage", Mencius is one of the principal interpreters of Confucius. He proposed many ideas such as the innate goodness of the individuals, benevolence, humane government and people as the foundation of the country. In Song dynasty, Zhu Xi compiled it as one of the Four Books representing the core of orthodox Neo-Confucian thought.

In Ming Dynasty, Mencius was first translated by the missioners into Latin and later into many European languages and 15 full and abridged versions in English. In 1828, David Collie translated Mencius into English for the first time. In 1861, the Scottish sinologist and Congregationalist, Dr. James Legge published Chinese Classics, among which Mencius was listed volume II and has been regarded as the standard version for decades with the loyal translation and numerous detailed notes. In the $20^{\text {th }}$ century, more and more western and Chinese scholars joined in the translation of the Chinese canon, such as Leonard Arthur Lyall, Lionel Giles, Ezra Pound, W.A. Dobson etc. However, many of these English versions are abridged or rearranged, which are at variance with the original Chinese version. In 1970, D. C. Lau's version was labeled as the most influential one with concise English and lengthy introduction. Among all the English versions translated by the Chinese, the Zhao Zhentao version is the most influential one.

Till now, the studies on Mencius have been rare on either the ideology or the English versions. John Makeham (2001) elaborates the westerners' interpretation of Mencius' ethics. James Behuniak (2005) introduces Mencius from the viewpoint of cosmological background, feeling and moral development. However, the research of Mencius' sentence structure and text has been rarely carried out. I compare three authoritative versions of James Legge, D.C. Lau and Zhao Zhentao to explore the translation strategies of the constant rheme progression, a special sentence structure in the book and present some suggestion to the translation.

\section{Translation of CONStant Rheme Progression in MENCIUS}

Composed of seven chapters, Mencius is a recording of his dialogues with the kings on benevolence, kingcraft and virtuous administration. The text is intelligent and sharp with eloquent argumentation and filled with rhetorics such as parallelism, antithesis, anadiplosis, simile and metaphors and all the thematic progressions which are widely and flexibly applied. The thematic progressions distribution in the book is illustrated in the following table.

TABLE 1.

THEMATIC PROGRESSIONS IN MENCIUS

\begin{tabular}{l|l|l|l|l|l}
\hline & Constant Theme & Linear Theme & Constant Rheme & Derived Theme & Split Rheme \\
\hline Numbers & 57 & 57 & 93 & 42 & 3 \\
\hline Percentage $(\%)$ & 22.6 & 22.6 & 36.9 & 16.7 & 1.2 \\
\hline
\end{tabular}

Through Table 1, we can find that constant rheme is rather frequent in Mencius. The progression is like epipophra or epistrophe in rhetorics, which are adopted in large number in each chapter. From the viewpoint of phonology, the sentences of constant rheme progressions sound sonorous and forceful. From semantic viewpoint, the relationship of different themes is presented to form an information chain to reinforce the rheme by the parallel structures of different themes.

The information unit in the rheme has been greatly emphasized as each clause is dependent on each other in the similar sentence structure. However, constant rheme progression is less explicit in English text. The translator is facing the dilemma of wordy literal translation or unfaithful free translation. I suggest several solutions to the problem on the basis of the translation versions of the sentence structure.

\section{A. Reproduction of Sentence Structure}

The symmetric balance in sentence and phonology has been valued and constantly used in Chinese. The bamboo-like sentences in Chinese often share the recurrent structure without conjunctives to achieve cohesion and rhetoric effect. As a result, constant rheme progressions are more popular in Chinese. While in English, the constant rheme is applied for rhetoric functions and more likely to be found in poems, speeches and dramas like Annabel Lee by Edgar Allan Poe and Shakespear's Tempest. Take The Grapes of Wrath by John Steinbeck as an example: "The movement changed them; the highways, the camps along the road, the fear of hunger and the hunger itself, changed them. The children without dinner changed them, the endless moving changed them"(2002, p.510). The sentences are impressive because the information focus is stressed through the repetition of rheme. In the case of foregrounding, the translator can keep the original structure in the translation to stress the information in the rheme. For example:

1) 鱼, 我所欲也, 熊掌亦我所欲也; 二者不可得兼, 舍鱼而取熊掌者也。(Book XI)

Pinyin: Yu wo suo yu ye, xiong-zhang yi wo suo yu ye. Er-zhe bu ke de jian, she yu er qu xiong-zhang ye.

Fish is what I want; bear's palm is also what I want. If I cannot have both, I would rather take bear's palm than fish. (D.C. Lau)

Fish is what I desire, and bear's paw is also what I desire; if I can not have both, I will give up fish and take bear's paw.(Zhao) 
The text develops in linear order and the readers receive the information sentence by sentence. The constant rheme progressions leave at each rheme a pause for the readers to digest and process the information and shift to next clause. In the three translation versions, James Legge keeps $54.3 \%$ of the constant rheme progressions into the target language, which is the most faithful to the original sentence structure. D. C. Lau maintains $38.1 \%$ of the constant rheme and Zhao Zhentao $38 \%$.

\section{B. Substitution and Ellipsis}

As the classical Chinese lacks systematic syntax and conjunctions, the context is constructed through the frequent repetition of the key words. Halliday(2008) holds that the system of cohesion is achieved by four ways of conjunction, reference, ellipsis and lexical organization. The translator can apply placeholding element such as "ones, the same, so" etc. to substitute the repeated information. For example:

2) 人知之, 亦器器; 人不知, 亦器器。(Book XIII)

Pinyin: Ren zhi zhi, yi xiaoxiao; ren bu zhi, yi xiaoxiao.

If a prince acknowledge you and follow your counsels, be perfectly satisfied. If no one do so, be the same. (J. Legge)

You should be content whether your worth is recognized by others or not. (D.C.Lau)

George Kingsley Zipf (1949) suggested that language is subject to the least effort principle which states that an information seeking client will tend to use the most convenient search method, in the least exacting mode available. Information seeking behavior stops as soon as minimally acceptable results are found. Generally speaking, the repetition of the same rheme is not frequent in English. The survey on 43 English essays indicates that the application of constant rheme is only $0.7 \%$. In the case of constant rheme recurring for over three times, the translator can use zero substitution or ellipsis to avoid that the information in the rheme repeats too intensively. For example:

3) 君子所以异于人者, 以其存心也。君子以仁存心, 以礼存心。(Book VIII)

Pinyin: Jun-zi suo-yi yi yu ren zhe, yi qi cun xin ye. Jun-zi yi ren cun xin, yi li cun xin.

That whereby the superior man is distinguished from other men is what he preserves in his heart;--namely, benevolence and propriety. (J. Legge)

A gentleman differs from other men in that he retains his heart. A gentleman retains his heart by means of benevolence and the rites. (D. C. Lau)

D.C. Lau applies zero substitution in $31.4 \%$ of the constant rheme progressions, while James Legge $16.2 \%$, and Zhao Zhentao $25.7 \%$. The application of substitution or ellipsis makes the version brief and conforms to the standard of the target language.

\section{Focus Permutation}

English and Chinese are different in culture and thought patterns. Robert Kaplan (1966,1972 and 1988) claims that English-speaking countries use direct expressions while the oriental people prefer roundabout and indirect patterns. The Chinese culture has been characterized by the indirectness in language and communication. The Chinese are postulated as having their own valued, or preferred and specifiable rhetorical patterns in discourse; and that is inductive or delayed introduction of the first or main topic in discourse. Conversely, a deductive pattern, i.e. early introduction of the topic, is used in western culture. The indirectness is reflected in the processing of information focus which is loaded with the most important information and what the speaker wants to stress in the text. It is more likely for the Chinese to place the information focus in the end of the sentence while the English tends to put it in the begging of the utterance. For example:

4)“独乐乐, 与人乐乐, 孰乐? 与少乐乐, 与众乐乐, 孰乐?”(Book II)

Pinyin: Du yue le, yu ren yue le, shu le? Yu shao yue le, yu zhong yue le, shu le?

Which is the more pleasant?- to enjoy music by your self alone, or to enjoy it with others? Which is the more pleasant,--to enjoy music with a few, or to enjoy it with many? (J. Legge)

Which is greater, enjoyment by yourself or enjoyment in the company of others? Which is greater, enjoyment in the company of a few or enjoyment in the company of many? (D.C. Lau)

The Chinese tends to apply inductive discourse pattern while the English deductive discourse pattern. When the rheme is a summary of the information, the constant rheme progressions can be transformed into constant theme progressions to stress the information focus in the very beginning. The focus permutation of James Legge, D.C. Lau and Zhao Zhentao are $17.1 \%, 19 \%$ and $24.8 \%$ respectively.

\section{SUMMARY AND CONCLUSION}

The functional analysis lays more emphasis upon the interrelationship between sentences in the text. The constant rheme progression forms a cohesive chain in which the information is reiterated and emphasized by repetition. The constant rheme progressions are rather common in Chinese classics such as Analects, Zhuangzi and The Art of War etc. The translator can apply different translation strategies on the basis of the intention of the author and the distribution of information to avoid information redundancy or undertranslation. The research on the constant rheme progression can help the translator organize the textual organization for the construction of a more coherent version of the constant rheme progression. 


\section{REFERENCES}

[1] Behuniak, James. (2005). Mencius on Becoming Human. Albany: State University of New York Press.

[2] Bloor, Thomas. \& Meriel Bloor. (2001). The Functional Analysis of English. Beijing: Foreign Language Teaching and Research Press.

[3] Danes, F. (1974). Functional Sentence Perspective and the Organization of the Text. Papers on Functional Sentence Perspective. Prague: Publishing House of the Czechoslovak Academy of Sciences. 106-128.

[4] Downing, A. (2001). Thematic Progression as a Functional Resource in Analyzing Text. Oxford: Oxford University Press.

[5] Halliday, M. A. K. (1994). An Introduction to Functional Grammar. London: Edward Arnold.

[6] Halliday, M. A.K. (2008). An Introduction to Functional Grammar. Beijing: Foreign Language Teaching and Research Press, 64, 534.

[7] Kaplan, R. (1966). Cultural Thought Patterns in Intercultural Education. Language Learning, 16(1-2), 1-20.

[8] Lau. D. C. (1970). Mencius. London: Penguin Group.

[9] Legge, James. (2008). The Works of Mencius. Beijing: Foreign Language Teaching and Research Press, 2010.

[10] Makeham, John. (2001). Interpreting Mencius. New Zealand Journal of Asian Studies 3, 1, 20-33.

[11] Mathesius, V. (1939). Functional Sentence Perspective. Prague: Academia.

[12] Steinbeck, John. (2002). The Grapes of Wrath and Other Writings, 1936-1941. New York: Library of America.510.

[13] Thompson, Geoff. (2008). Introducing Functional Grammar. Beijing: Foreign Language Teaching and Research Press.

[14] Xu Shengheng. (1982). Theme and Rheme. Foreign Language Teaching and Research, 1, 1-9.

[15] Zhao Zhentao. (1999). Mencius. Beijing: Foreign Languages Press.

[16] Zipf, G. K. (1949). Human Behavior and the Principle of Least Effort: An Introduction to Human Ecology. Boston: Addison-Wesley Press.

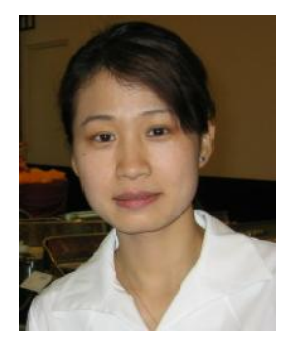

Yuan Tao, born in Haerbin, Heilongjiang Province in 1975, is a lecturer of the School of Foreign Languages in Dalian University of Technology. Main areas of her expertise include translation studies, linguistics and applied linguistics, content-based instruction in teaching.

She has taught English for 8 years and her representative publications include Application of Antithesis in English-Chinese Translation from Functionalist Translation Theory, Thematic Progression in EST and the Translation, Non-English Major Translation Teaching on the Basis of CBI etc., and she also published and translated several books. 